\title{
Eversion Carotid Endarterectomy : A Short Review
}

\author{
Lazar B. Davidovic, ${ }^{1,2}$ Ivan Z. Tomic ${ }^{2}$ \\ School of Medicine,' University of Belgrade, Belgrade, Serbia \\ Clinic for Vascular and Endovascular Surgery, ${ }^{2}$ Clinical Center of Serbia, Belgrade, Serbia
}

Carotid endarterectomy (CEA) is the main procedure in carotid surgery, as well as the most frequent vascular procedure. Two techniques of CEA are available : eversion and conventional plus patch angioplasty. Eversion CEA is anatomic procedure that reduces ischemic and total operative time. Simultaneous correction of the joined carotid kinking and coiling is possible, easy and safe, while the usage of patch is excluded. Thanks to oblique shape of anastomosis, eversion CEA is associated with low risk of long-term restenosis. The false anastomotic aneurysms occurrence is very rare, almost impossible after eversion CEA. However, the usage of carotid shunt during eversion CEA is not always simple, while proximal or distal extension of the carotid plaque can make eversion CEA more difficult and risky. Eversion CEA should be the first choice in carotid surgery. Conventional CEA is indicated in cases when carotid plaque is extended more than usual, as well as, if the usage of carotid shunt is necessary.

Key Words : Endarterectomy · Eversion · Carotid · Artery.

\section{HISTORICAL BACKGROUND}

In the fifties of the last century, the first successful carotid artery reconstructions were performed. In 1951 in Argentina Carrea, Molins and Murphy performed an exclusion (ligature) of the sick (stenosed) proximal segment of the internal carotid artery (ICA), as well as end-to-end anastomosis between proximal segment of an external carotid artery (ECA) and distal patent segment of $\mathrm{ICA}^{10)}$. After an excision of stenosed common carotid artery (CCA) Eastcott, Pckering and Rob performed direct end-to-end anastomosis between the CCA and ICA. The carotid artery was clamped for 28 minutes. During the procedure patient's body temperature has been reduced to 28 degrees by external cooling ${ }^{16)}$. That procedure has been performed in London in 1954. In the same year Denman et al. ${ }^{14)}$ resected the occluded segment of the ICA, and restored arterial flow with homograft. During the next year Doyle et al. ${ }^{15)}$ used saphenous vein graft for the reconstruction during the same procedure.

All previous procedures are performed relative rare in carotid surgery. The main procedure is carotid endarterectomy (CEA). The first CEA has been performed by famous Michael De Bakey, the "father" of modern cardiovascular surgery in 1953. However, De Bakey et al. ${ }^{13)}$ published article about that procedure in 1959, which was absolutely untypical for him. In that article De Bakey and his coworkers have explained two techniques of CEA : conventional and eversion. Conventional CEA begins with longitudinal incision of the CCA and ICA

- Received : October 3, 2019 •Revised : November 18, 2019 •Accepted : December 29, 2019

- Address for reprints : Ivan Z. Tomic

Clinic for Vascular and Endovascular Surgery, Clinical Center of Serbia, Koste Todorovića Street 8, Belgrade 11000, Serbia

Tel : +381 113065 176, Fax : +381 113065 177, E-mail : iv.tomic@yahoo.com, ORCID : https://orcid.org/0000-0003-2460-8259

This is an Open Access article distributed under the terms of the Creative Commons Attribution Non-Commercial License (http://creativecommons.org/licenses/by-nc/4.0) which permits unrestricted non-commercial use, distribution, and reproduction in any medium, provided the original work is properly cited. 
over carotid plaque. After a removing of the plaque longitudinal arteriotomy can be closed directly or by using patch. In the same paper De Bakey and coworkers explained eversion CCA as well. That procedure did not require the usage of carotid patch. Arterial continuity was restored by end-to-end anastomosis $^{6}$. Seventeen years after De Bakey initial procedure an eversion technique was again popularized by Etheredge $^{18)}$. However, besides that a conventional CEA has been dominant procedure in carotid surgery for the following few decades. At the beginning of the last decade of the ninetieth century Kasprzak and Raithel ${ }^{19)}$ and Vanmaele et al. ${ }^{28)}$ developed new modification of the eversion CEA.

\section{TECHNIQUES FOR AN EVERSION CEA}

Two modifications of an eversion CEA are available in nowadays surgical practice. De Bakey-Etheredge modification of the eversion CEA is indicated if atherosclerotic process involves mostly CCA bifurcation (Fig. 1) ${ }^{13,18)}$.

In such cases the procedure begins with the transection of

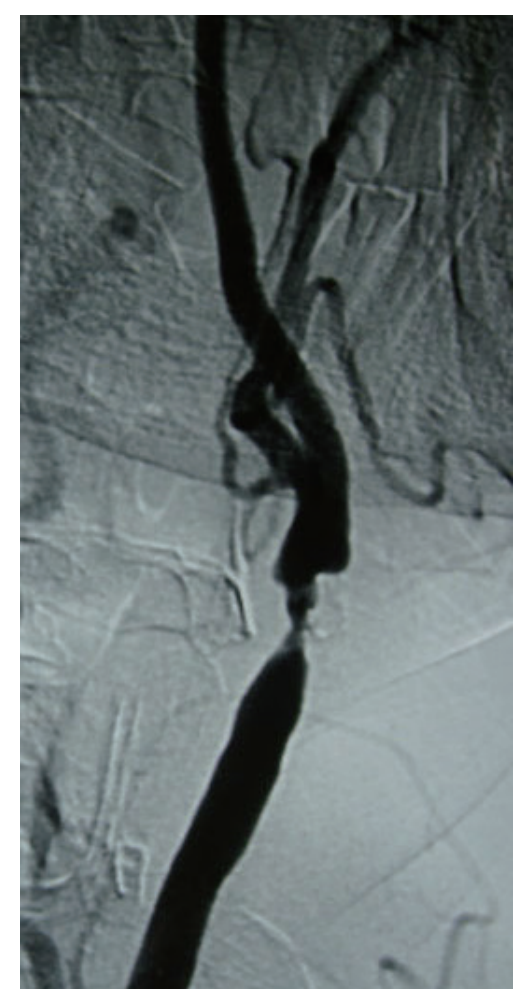

Fig. 1. Atherosclerotic involvement of common carotid artery bifurcation - angiographic review. the CCA at a level 0.5 to $1.0 \mathrm{~cm}$ proximal to tile bifurcation as seen in Fig. 2. It is not recommendable to get to close to the bifurcation since the carotid plaque sometimes extends more proximally than usually ${ }^{18)}$.

It is followed with distal eversion endarterectomy of the ECA and ICA (Fig. 3). A "mosquito" is most helpful in starting the plane of the dissection ${ }^{13,18)}$. The type of peeling back used in circumcision is the key to the success of the entire operation since it affords visualization the way out to the tip of the plaque ${ }^{18)}$. Thanks to that it is possible to see the distal end of the plaque prior it's removing. The next step is proximal eversion endarterectomy of the CCA. A proximal endarterectomy should carry back for at least $2 \mathrm{~cm}$ to have equal structures for reanastomosis (Fig. 4) ${ }^{18)}$. A final step is re-anastomosis using simple over and over continuous suture (Fig. 5).

When the anastomosis has been completed, the clamps are removed in a specific order in an effort to prevent embolism. An ICA clamp is removed firstly for the distal flushing. After that the ICA is occluded temporarily at it's origin by a vascular forceps or fingers, while the external and common carotid clamps are being removed. We perform this procedure with-

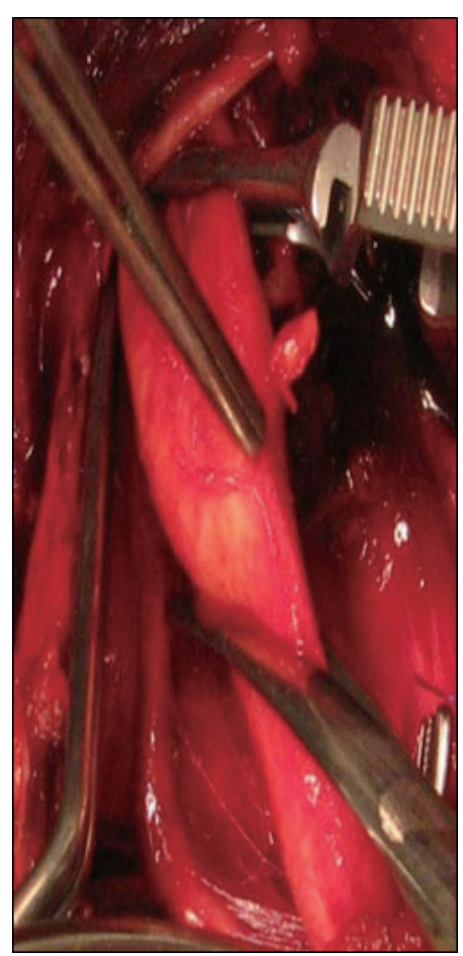

Fig. 2. De Bakey-Etheredge modification of the eversion carotid endarterectomy : transection of common carotid artery - intraoperative review. 
out usage of carotid shunt since its placement is difficult ${ }^{21)}$.

Previously described modification of an eversion CEA sometimes leaves the distal intima edge uncertain ${ }^{7}$. Due to this Kasprzak-Raithel-Vanmaele modification of the eversion CEA is indicated if atherosclerotic process involves mostly ICA (Fig. 6) ${ }^{19,28)}$. This procedure begins with oblique transection of the ICA from $\mathrm{CAA}^{19)}$ (Fig. 7).

That is followed with the distal eversion endarterectomy of the ICA. This is done in the same way as already described distal eversion endarterectomy during De Bakey-Etheredge modi-

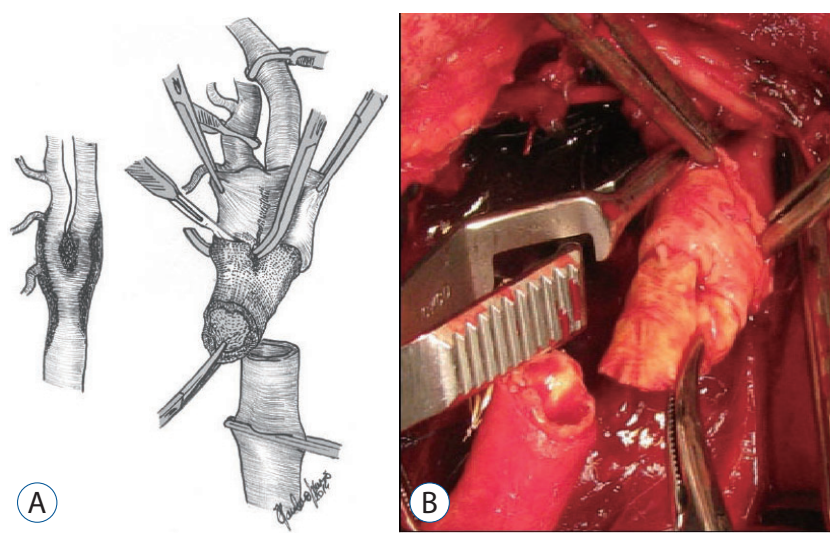

Fig. 3. De Bakey-Etheredge modification of the eversion carotid endarterectomy : distal eversion endarterectomy of internal and external carotid artery (A) shematic review and (B) intraoperative review.

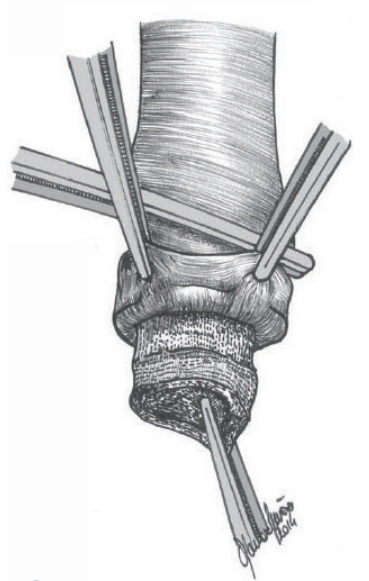

(A)

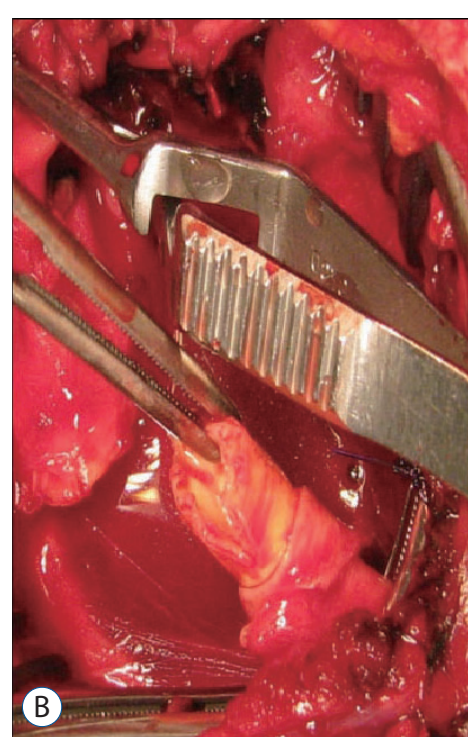

Fig. 4. De Bakey-Etheredge modification of the eversion carotid endarterectomy : proximal endarterectomy of common carotid artery (A) shematic review and (B) intraoperative review. fication (Fig. 8) ${ }^{13,18)}$. After the direct endarterectomy of the CCA and ECA if it is necessary, the final step is reattachment of end-

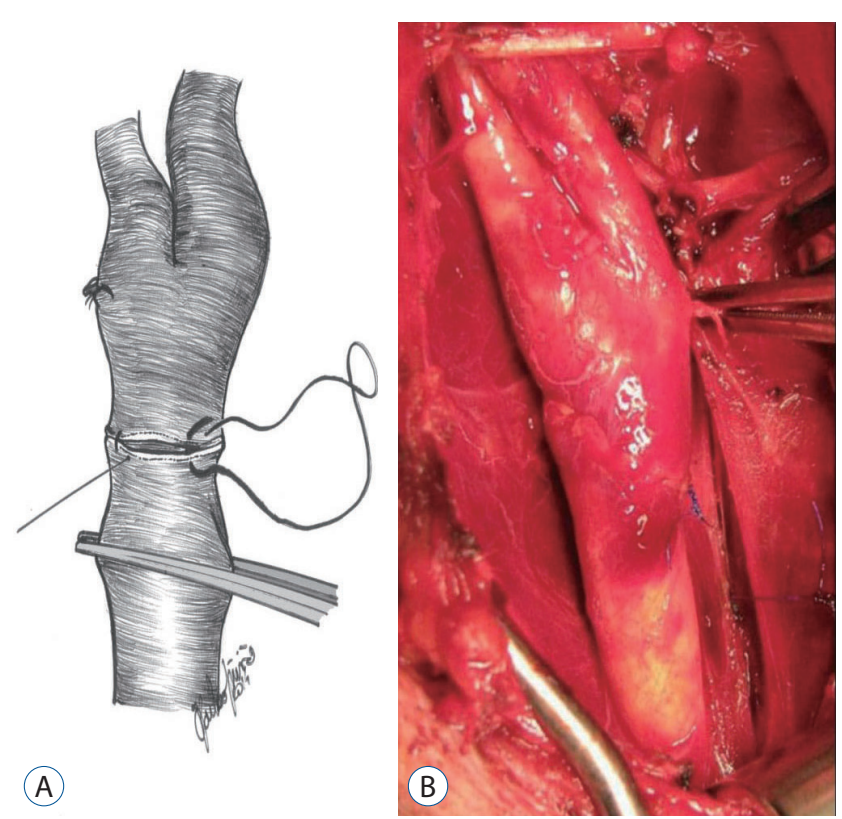

Fig. 5. De Bakey-Etheredge modification of the eversion carotid endarterectomy : reanastomosis (A) shematic review and (B) intraoperative review.

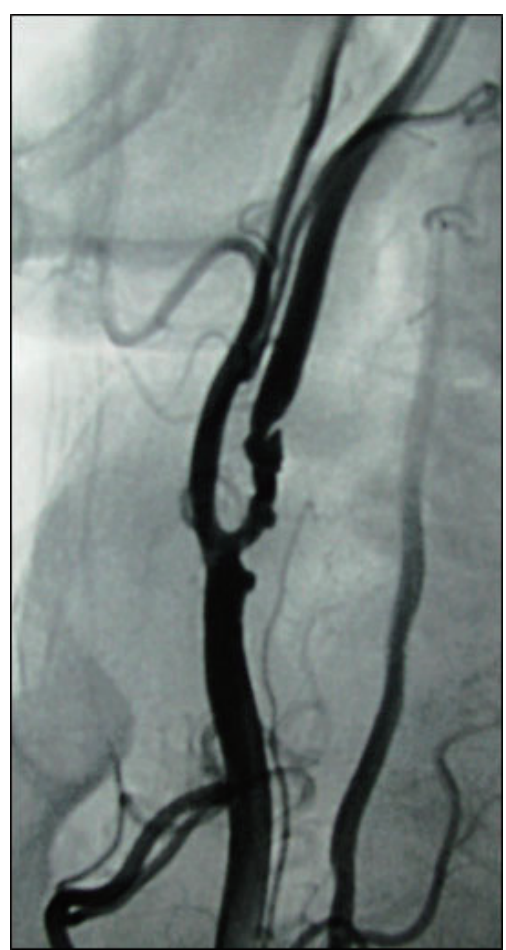

Fig. 6. Atherosclerotic involvement of internal carotid artery - angiographic review. 

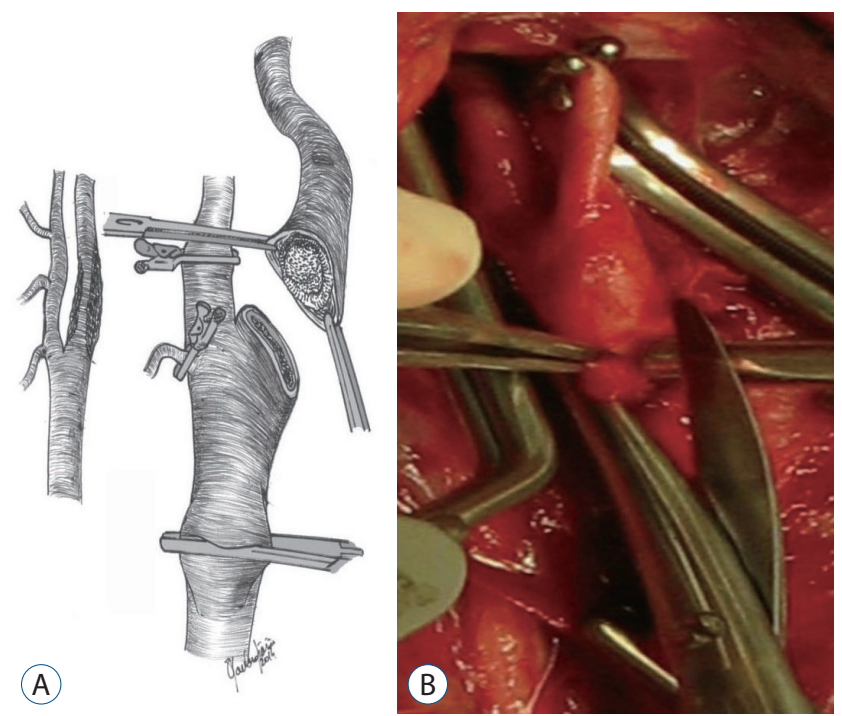

Fig. 7. Kasprzak-Raithel-Vanmaele modification of the eversion carotid endarterectomy : oblique transection of internal carotid artery from the common carotid artery (A) shematic review and (B) intraoperative review.
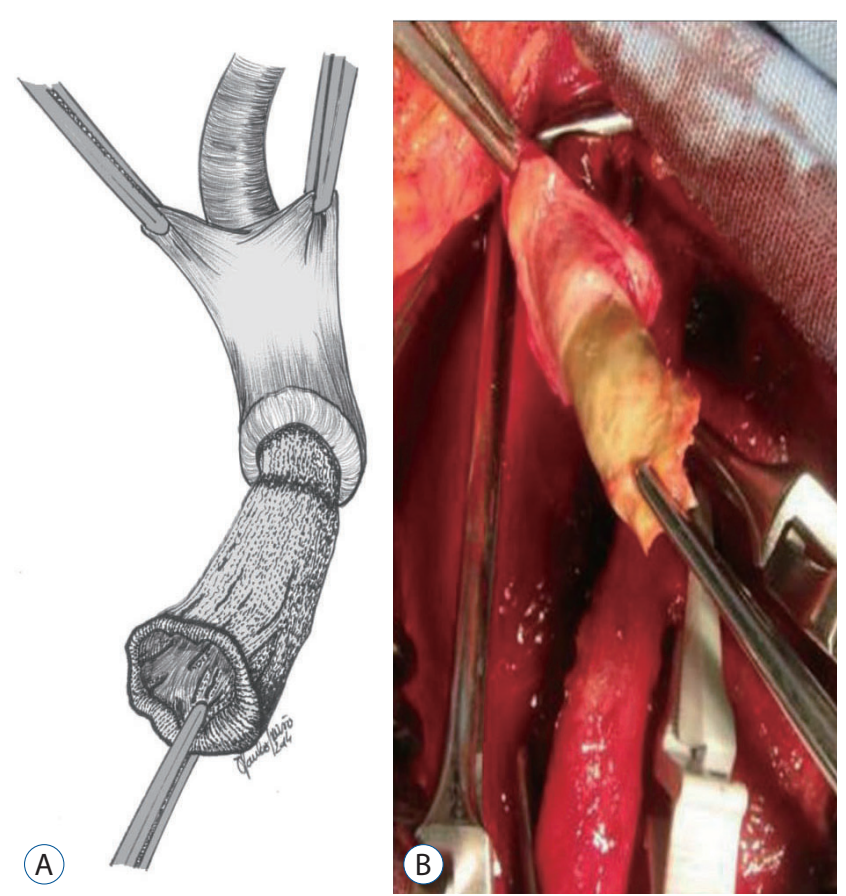

Fig. 8. Kasprzak-Raithel-Vanmaele modification of the eversion carotid endarterectomy : distal endarterectomy of internal carotid artery (A) shematic review and (B) intraoperative review.

arterctomized ICA (Fig. 9) ${ }^{19,28)}$.

A removing of the clamps and prevention of brain embolization is already described. The usage of carotid shunt is not
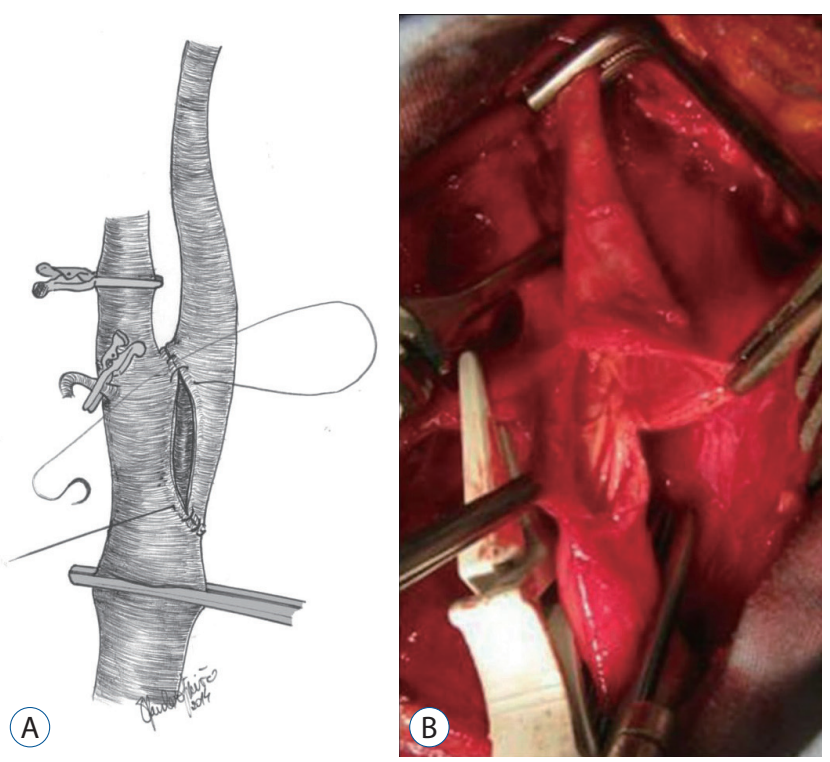

Fig. 9. Kasprzak-Raithel-Vanmaele modification of the eversion carotid endarterectomy : reattachment of endarterctomized internal carotid artery (A) shematic review and (B) intraoperative review.

also simple during this procdure ${ }^{21)}$.

\section{COMPARISON OF EVERSION AND CONVEN- TIONAL TECHNIQUES}

Numerous studies have compared conventional CEA plus patching with eversion one $\mathrm{e}^{3,5-9,11,17,20,21,29)}$. Regarding the total operating and ischemic time, as well as perioperative complications, first studies have favored to eversion $\mathrm{CEA}^{17,29)}$. One of these studies that compared conventional and eversion CEA has been conducted and designed in a truly interesting manner. Namely, on the one carotid artery at the same patient, Ballotta and associates performed eversion, while on another side conventional CEA. Regarding early and long term results, eversion CEA has been better ${ }^{3,4)}$. After that the first randomized prospective multicenter study followed. It has been EVEREST (Eversion Carotid Endarterectomy versus Standard Trial Study) performed in Italy. A total of 1353 patients with carotid stenosis requiring surgical treatment were randomly assigned to received standard $(\mathrm{n}=675)$ or eversion $(\mathrm{n}=678)$. Primary endpoints included carotid occlusion, major stroke, death, and restenosis rate ${ }^{5-9}$. According to preliminary results, eversion CEA reduced clamping time and probability of restenosis $^{5}$. Their following results confirmed lower incidence of 
mid and long-term restenosis after eversion $\mathrm{CEA}^{6,7)}$. Few years later, authors of EVERST study concluded that significantly reduced restenosis after eversion CEA, did not appear to be associated with clinical benefit in terms of reduced stroke risk, either preoperatively or later"). In Cochrane review from 2009 that included a total of 2465 patients with 2589 arteries, authors of EVEREST trial did not find a significant differences in the rate of perioperative stroke and/or death (1.7\% vs. $2.6 \%$; odds ratio [OR], $0.44 ; 95 \%$ confidence interval [CI], 0.10-1.82) and stroke during follow-up (1.4\% vs. $1.7 \%$; OR, 0.84 ; $95 \% \mathrm{CI}$, 0.43-1.64) between eversion and conventional CEA techniques. They concluded that only one advantage of eversion endarterectomy is low risk of carotid restenosis and occlusion ${ }^{8)}$.

According to our prospective, randomized single center study which included 201 patients who were followed approximately 37.7 months, eversion CEA significantly reduced clamping and operating times, the early stroke rate, as well as long-term restenosis ${ }^{21)}$.

In 2011 a meta-analysis with more than 21 studies (seven randomized and 14 non-randomized) and more than 16000 patients was published. A study from our Clinic is included as well ${ }^{21}$. This meta-analysis revealed that eversion CEA significantly reduces perioperative stroke (OR, 0.46; 95\% CI, 0.350.62 ; numbers needed to treat [NNT], 68; 95\% CI, 56-96) and death outcomes (OR, 0.49; 95\% CI, 0.34-0.69; NNT, 100; 95\% CI, 85-185), as well as long-term carotid occlusion (OR, 0.48; 95\% CI, 0.25-0.90; NNT, 143; 95\% CI, 100-769) and mortality (OR, 0.76; 95\% CI, 0.61-0.94; NNT, 40; 95\% CI, 25-167)

An updated systemic review that analysed randomized controlled trials and observational studies was publisehed in 2018. According to this paper an eversion CEA was superior to conventional once regarding peri-operative outcomes (death, stroke, death/stroke, and late restenosis). However, when eversion CEA outcomes were compared with outcomes after patched CEA, there were no significant differences ${ }^{23)}$.

Besides previous facts recommendations regarding technique of the CEA from the current European Society for Vascular Surgery guidelines are not clear ${ }^{22}$. According to it the choice between eversion and "patched" endarterectomy should be left to the discretion of the operating surgeon. However, let us face some facts ${ }^{1,3,5-9,11,17,20,21,23,29)}$. Eversion CEA is anatomic procedure that reduces ischemic and total operative time. Then, the usage of patch is excluded. Simultaneous correction of the joined kinking and coiling is possible, easy and safe. Eversion CEA, which employs an oblique arteriotomy and re-implantation of the ICA or end-to-end anastomosis between proximal and distal segments of the CCA, is reported to be associated with low restenosis. The false anastomotic aneurysms occurrence during the follow-up period is almost impossible. However eversion CEA has also some disadvatages. The usage of carotid shunt during eversion CEA is not always simple, easy and safe. Extension of the atherosclerotic process towards proximally or distally can make eversion CEA more difficult and risky. The first reason is an increased risk of complications associated with a distal intimal flap ${ }^{28}$. In cases of extensive atherosclerotic stenosis of the common carotid artery, eversion CEA may leave a step at its proximal end. According to some opinions, the presence of a step greater than $2 \mathrm{~mm}$ could cause brain embolism and accelerates local restenosis ${ }^{2}$.

Recommendations from the current European Society for Vascular Surgery guidelines regarding the usage of shunt are also not clear ${ }^{22)}$. According to it the choice of shunting is also left to the discretion on the operating surgeon. On the other hand one of our studies did not find that the usage of shunt reduce the incidence of perioperative stroke occurrence ${ }^{12)}$. Due to this we use the following strategy regarding the usage of shunt during $\mathrm{CEA}^{25-27)}$. We perform CEA under cervical plexus block anesthesia. Following carotid dissection, a trial carotid artery clamming is performed that lasts 3 minutes. If there are no changes in patient's neurological state after this period, an eversion CEA without the usage of shunt is performed. In case that neurological changes occur, clamping is stopped until patient recovery. Then new clamping follows, a common carotid artery is opened longitudinally, a shunt is placed and conventional CEA is performed. Thanks to previous strategy, we improved early results and significantly reduced the usage of carotid shunt from 37\% at the period between 2000 and 2003 , to only $7 \%$ during last years ${ }^{12,21,25-27)}$. Namely, beside well known advantages, the usage of carotid shunt also has some disadvantages. Those are the risk of brain embolization and ICA dissection. Finally, in the presence of the carotid shunt, sometimes it is not so easy to perform CEA. Also, a significant technical problem of both, eversion and conventional endarterectomy is existence of a highly positioned carotid bifurcation (level of first and second cervical vertebra), such as is often the case in Asian population. Theoretically, in such situations we have at our disposal a different "high" surgical 
approaches. Some of them are : resection of posterior part of digastric muscle, anterior subluxation of the mandible, stiloidectomy with resection of stiloid muscles, mandibular osteotomy and posterolateral approach with resection of mastoid exten$\operatorname{sion}^{24)}$. However, even the most experienced vascular surgeons are not familiar with these techniques in everyday practice. Because of this, in the modern era a method of choice in our institution is carotid angioplasty with stent placement.

\section{CONCLUSION}

Eversion CEA, performed by an experienced surgeon, is safe, effective, and durable procedure. It reduces ischemic and total operative time, as well as, restenosis and false anastomotic aneurysms occurrence during the follow-up period. Due to this eversion CEA should be the first choice in carotid surgery. Conventional CEA is indicated in cases when carotid plaque is extended more than usual, as well as, if the usage of external shunt is necessary.

\section{CONFLICTS OF INTEREST}

No potential conflict of interest relevant to this article was reported.

\section{INFORMED CONSENT}

This type of study does not require informed consent.

\section{AUTHOR CONTRIBUTIONS}

\author{
Conceptualization : LD, IT \\ Data curation : LD, IT \\ Formal analysis : LD, IT \\ Funding acquisition : LD, IT \\ Methodology : LD, IT \\ Project administration : LD, IT \\ Visualization : LD, IT \\ Writing - original draft : LD, IT \\ Writing - review \& editing: LD, IT
}

\section{ORCID}

Lazar B. Davidovic https://orcid.org/0000-0002-0529-2378

Ivan Z. Tomic https://orcid.org/0000-0003-2460-8259

\section{- Acknowledgements}

Presented study is a part of a scientific research project (No 175008) supported by the Ministry of Education and Science of the Republic of Serbia.

\section{References}

1. Antonopoulos CN, Kakisis JD, Sergentanis TN, Liapis CD : Eversion versus conventional carotid endarterectomy: a meta-analysis of randomised and non-randomised studies. Eur J Vasc Endovasc Surg 42 : 751 765, 2011

2. Archie JP : The endarterectomy-produced common carotid artery step: a harbinger of early emboli and late restenosis. J Vasc Surg 23 : 932939, 1996

3. Ballotta E, Da Giau G, Saladini M, Abbruzzese E, Renon L, Toniato A : Carotid endarterectomy with patch closure versus carotid eversion endarterectomy and reimplantation: a prospective randomized study. Surgery $125:$ 271-279, 1999

4. Ballotta E, Renon L, Da Giau G, Toniato A, Baracchini C, Abbruzzese E, et al. : A prospective randomized study on bilateral carotid endarterectomy: patching versus eversion. Ann Surg 232 : 119-125, 2000

5. Cao P, Giordano G, De Rango P, Caporali S, Lenti M, Ricci S, et al. : Eversion versus conventional carotid endarterectomy: a prospective study. Eur J Vasc Endovasc Surg 14 : 96-104, 1997

6. Cao P, Giordano G, De Rango P, Zannetti S, Chiesa R, Coppi G, et al. : A randomized study on eversion versus standard carotid endarterectomy: study design and preliminary results: the Everest trial. J Vasc Surg 27 : 595-605, 1998

7. Cao P, Giordano G, De Rango P, Zannetti S, Chiesa R, Coppi G, et al. : Eversion versus conventional carotid endarterectomy: late results of a prospective multicenter randomized trial. J Vasc Surg 31(1 Pt 1) : 1930,2000

8. Cao PG, de Rango P, Zannetti S, Giordano G, Ricci S, Celani MG : Eversion versus conventional carotid endarterectomy for preventing stroke. Cochrane Database Syst Rev (1) : CD001921, 2001

9. Cao PG, De Rango P, Zannetti S : Eversion vs conventional carotid endarterectomy: a systematic review. Eur J Vasc Endovasc Surg 23 : 195-201, 2002

10. Carrea $R$ : Surgical treatment of spontaneous thrombosis of the internal carotid artery in the neck. Carotid-carotideal anastomosis; report of a case. Acta Neurol Lat Am 1 : 71-78, 1955

11. Chen $G Z$, Wu YZ, Diao PY, Ma L, Yan S, Chen XY, et al. : Comparison 
of eversion carotid endarterectomy and patch carotid endarterectomy: a retrospective study of 6 years of experience. Med Sci Monit 24 : 5820-5825, 2018

12. Davidovic L, Koncar I, Dragas M, Markovic M, llic N, Mutavdzic $P$, et al. : Female and obese patients might have higher risk from surgical repair of asymptomatic carotid artery stenosis. Ann Vasc Surg 29 : 1286-1292, 2015

13. De Bakey ME, Crawford ES, Cooley DA, Morris CG Jr : Surgical considerations of occlusive disease of innominate, carotid, subclavian, and vertebral arteries. Ann Surg $149:$ 690-710, 1959

14. Denman FR, Ehni G, Duty WS : Insidious thrombotic occlusion of cervical carotid arteries, treated by arterial graft; a case report. Surgery 38 : 569-577, 1955

15. Doyle EJ, Javid H, Lin PM : Partial internal carotid artery occlusion treated by primary resection and vein graft; report of a case. J Neurosurg 13 : 650-655, 1956

16. Eastcott HH, Pickering GW, Rob CG : Reconstruction of internal carotid artery in a patient with intermittent attacks of hemiplegia. Lancet 267 : 994-996, 1954

17. Entz $L$, Járányi $S$, Nemes $A$ : Eversion endarterectomy in surgery of the internal carotid artery. Cardiovasc Surg 4 : 190-194, 1996

18. Etheredge $S N$ : A simple technic for carotid endarterectomy. Am J Surg $120: 275-278,1970$

19. Kasprzak $P$, Raithel $D$ : Eversionsendarteriektomie der Arteria carotis interna. Angio $12: 1-8,1990$

20. Littooy FN, Gagovic V, Sandu C, Mansour A, Kang S, Greisler HP : Comparison of standard carotid endarterectomy with Dacron patch angioplasty versus eversion carotid endarterectomy during a 4-year period. Am Surg 70 : 181-185; discussion 185, 2004

21. Markovic DM, Davidovic LB, Cvetkovic DD, Maksimovic ZV, Markovic $D Z$, Jadranin DB : Single-center prospective, randomized analysis of conventional and eversion carotid endarterectomy. J Cardiovasc Surg (Torino) 49 : 619-625, 2008
22. Naylor AR, Ricco JB, de Borst GJ, Debus S, de Haro J, Halliday A, et al. : Editor's choice - management of atherosclerotic carotid and vertebral artery disease: 2017 clinical practice guidelines of the European Society for Vascular Surgery (ESVS). Eur J Vasc Endovasc Surg 55 : 3-81, 2018

23. Paraskevas KI, Robertson V, Saratzis AN, Naylor AR : Editor's choice an updated systematic review and meta-analysis of outcomes following eversion vs. conventional carotid endarterectomy in randomised controlled trials and observational studies. Eur J Vasc Endovasc Surg 55 : 465-473, 2018

24. Pellegrini RV, Manzetti GW, DiMarco RF, Bekoe S, Arena SA, Marrangoni $A G$ : The direct surgical management of lesions of the high internal carotid artery. J Cardiovasc Surg (Torino) 25 : 29-35, 1984

25. Sindjelic R, Davidovic L, Vlajkovic G, Markovic M, Kuzmanović I : Pain associated with carotid artery surgery performed under carotid plexus block: preemptive analgesic effect of ketorolac. Vascular 14 : 75-80, 2006

26. Sindjelic RP, Vlajkovic GP, Davidovic LB, Markovic DZ, Markovic MD : The addition of fentanyl to local anesthetics affects the quality and duration of cervical plexus block: a randomized, controlled trial. Anesth Analg $111: 234-237,2010$

27. Sindjelic RP, Vlajkovic GP, Lucic M, Koncar I, Kostic D, Davidovic LB : Incidence of and indications for conversion of cervical plexus block to general anesthesia in patients undergoing carotid surgery: a single center experience. J Cardiovasc Surg (Torino) $56:$ 441-446, 2015

28. Vanmaele R, Van Schil P, De Maeseneer M : Closure of the internal carotid artery after endarterectomy: the advantages of patch angioplasty without its disadvantages. Ann Vasc Surg 4 : 81-84, 1990

29. Vanmaele RG, Van Schil PE, DeMaeseneer MG, Meese G, Lehert P, Van Look RF : Division-endarterectomy-anastomosis of the internal carotid artery: a prospective randomized comparative study. Cardiovasc Surg 2 : 573-581, 1994 